\title{
A theoretical study of possible point defects incorporated into alpha-alumina deposited by chemical vapor deposition
}

C. Arhammar, F. Silvearv, A. Bergman, S. Norgren, Henrik Pedersen and R. Ahuja

\section{Linköping University Post Print}

\section{Tweet}

N.B.: When citing this work, cite the original article.

The original publication is available at www.springerlink.com:

C. Arhammar, F. Silvearv, A. Bergman, S. Norgren, Henrik Pedersen and R. Ahuja, A theoretical study of possible point defects incorporated into alpha-alumina deposited by chemical vapor deposition, 2013, Theoretical Chemistry accounts, (133), 2, 1433.

http://dx.doi.org/10.1007/s00214-013-1433-x

Copyright: Springer Verlag (Germany) http://www.springerlink.com/?MUD=MP

Postprint available at: Linköping University Electronic Press http://urn.kb.se/resolve?urn=urn:nbn:se:liu:diva-103716 
A theoretical study of possible point defects incorporated into $\alpha$-alumina deposited by Chemical Vapor Deposition

\author{
C.Århammar ${ }^{1}$, F. Silvearv ${ }^{2}$, A. Bergman ${ }^{3}$, S. Norgren ${ }^{1,4}$, H. \\ Pedersen $^{5}$, and R. Ahuja ${ }^{3}$
}

${ }^{1}$ Sandvik Coromant, Lerkrogsv. 13, SE 126-80 Stockholm, Sweden

${ }^{2}$ Applied Physics, Division of Material Science, Department of Engineering Sciences and Mathematics, Luleå University of Technology, SE - 97187 Luleå, Sweden

${ }^{3}$ Division of Materials Theory, Department of Physics and Astronomy, Box 530, Uppsala University, S-751 21 Uppsala, Sweden

${ }^{4}$ Dept. of Engineering Sciences, Applied Materials Science -Tribology group, Ångström Laboratory, Uppsala University, Sweden

${ }^{5}$ Department of Physics, Chemistry and Biology, Linköping University, SE-581 83 Linköping, Sweden

November 12, 2013

\begin{abstract}
The energetics and electronic structure of carbon, chlorine, hydrogen and sulfur in $\alpha-\mathrm{Al}_{2} \mathrm{O}_{3}$ was investigated by ab initio and thermodynamical calculations. These species are present in the gas phase during synthesis of $\alpha-\mathrm{Al}_{2} \mathrm{O}_{3}$ by Chemical Vapor Deposition (CVD) but little is known of their solubility in this compound. The heat of formation from standard reference states of the elements, varying the chemical potential of each element was calculated. An attempt to model the
\end{abstract}


actual conditions in the CVD-process was made, using the species and solid compounds present in a common CVD-process as reference states. Our calculations suggest that sulfur from the catalysing agent $\mathrm{H}_{2} \mathrm{~S}$ will not solve in $\alpha-\mathrm{Al}_{2} \mathrm{O}_{3}$ during deposition by CVD. It is found that the neutral chlorine and hydrogen interstitial defects display the lowest heat of formation, 281 and $280 \mathrm{~kJ} / \mathrm{mol}$, respectively, at the modeled CVD-conditions. This energy is too high in order for neutral defects to form during CVD of $\alpha-\mathrm{Al}_{2} \mathrm{O}_{3}$ at any significant amounts. The charged defects and their compensation was studied. Carbon substituting oxygen is found to be energetically favored under the modeled CVD-conditions, considering carbon dioxide as competing species to solid solubility in $\alpha-\mathrm{Al}_{2} \mathrm{O}_{3}$. Compensation of carbon substituting for oxygen by oxygen vacancies takes place at $110 \mathrm{~kJ} / \mathrm{mol}$ from standard reference states, graphite, fcc- $\mathrm{Al}$ and $\mathrm{O}_{2}$. The carbon solubility in $\mathrm{Al}_{2} \mathrm{O}_{3}$ is difficult to measure with standard analysis techniques such as X-ray Diffraction and Energy Dispersive X-ray spectroscopy, but several stable compounds in the $\mathrm{Al}-\mathrm{C}-\mathrm{O}$ are available in the literature.

\section{Introduction}

For many years aluminum oxide, $\mathrm{Al}_{2} \mathrm{O}_{3}$, has been one of the most important coating materials used for metal cutting tools. The first $\mathrm{Al}_{2} \mathrm{O}_{3}$ coated tungsten carbide cutting insert from Sandvik Coromant was introduced already in 1975 and the improved wear properties of Chemical Vapor Deposition (CVD) coated cemented carbide tools has been known and studied for equally long time [42]. Due to the great impact which CVD-alumina, and other CVDcoatings e. g. TiC, TiN and TiCN, have had on the cutting tool industry, much work and effort has been focused on the understanding as well as developing the CVD-process for $\mathrm{Al}_{2} \mathrm{O}_{3}$ deposition [27, 28, 31, 16, 12, 21, 38]. The most important findings include:

$(i)$ the introduction of better controlled nucleation steps at the beginning of the CVD-process which allows single phase and fine-grained $\alpha-\mathrm{Al}_{2} \mathrm{O}_{3}$ to be deposited. Furthermore, by careful control of the $\alpha-\mathrm{Al}_{2} \mathrm{O}_{3}$ nucleation, the texture of the coating can also be controlled [30, 29].

(ii) the findings by Smith and Lindström et al. [44] that hydrogen disulfide $\left(\mathrm{H}_{2} \mathrm{~S}\right)$ could be used as a catalyst and did not only enhance the overall deposition rate but also to suppress the so called dog-bone effect.

This leads to thicker coatings on the edges of the inserts, and was a major discovery [44]. Recently we investigated the $\mathrm{H}_{2} \mathrm{~S}$ influence on the thermodynamics and kinetics of $\alpha-\mathrm{Al}_{2} \mathrm{O}_{3}$ formation and found that $\mathrm{H}_{2} \mathrm{~S}$ acts as mediator for the oxygenation of the aluminum surface which will in turn in- 
crease the growth rate of $\mathrm{Al}_{2} \mathrm{O}_{3} \cdot[8]$ Another research theme in $\mathrm{Al}_{2} \mathrm{O}_{3}$ CVD has been studies of the impact of trace elements on the growth of alumina. The trace elements studied have mainly been possible contaminants from the reactor walls and the substrate e.g. iron, cobalt and chromium [3] but also the effect of intentional dopants added to the growth process, such as boron and titanium [19] have been studied. Moreover, the co-deposition of $\mathrm{Al}_{2} \mathrm{O}_{3}$ and $\mathrm{ZrO}_{2}$ has been investigated, both as $\mathrm{ZrO}_{2} / \mathrm{Al}_{2} \mathrm{O}_{3}$ multilayers [7] and with the Al- and Zr-precursors combined in the growth process [39, 33]. The CVD deposition of alumina is today a routine process for coating thousands of cemented carbide inserts per batch. Although the overall chemistry in the process has been under careful investigation for many years and the control of the growing $\mathrm{Al}_{2} \mathrm{O}_{3}$ coating is mastered in terms of phase stability and texture control, not many details are known of possible crystal defects present in the grown alumina. Alumina is known as a very pure coating material, at least when synthesized under equilibrium conditions. However, low defect contents are difficult to detect using standard analysis techniques such as X-Ray Diffraction (XRD) and Wave length/Energy Dispersive Spectroscopy (WDS/EDS).

Thus, reports on point defects in CVD grown alumina are scarce. Schmidt et al. studied carbon inclusion in $\mathrm{Al}_{2} \mathrm{O}_{3}$ grown by high vacuum CVD using dimethyl aluminum isopropoxide [43], which is a quite different process compared to the standard low pressure alumina CVD process using $\mathrm{AlCl}_{3} / \mathrm{CO}_{2} / \mathrm{H}_{2} / \mathrm{H}_{2} \mathrm{~S}$. Andersson et al. [5] studied the effect of $\mathrm{Cr}$, Mo, Co and As replacing $\mathrm{Al}$ and of $\mathrm{N}$ and $\mathrm{S}$ substituting for oxygen in $\alpha$ and $\theta-\mathrm{Al}_{2} \mathrm{O}_{3}$ by first principles theory. They found that the relative stability of the $\theta$ - and $\alpha$-phase could be altered or even reversed by the addition of dopants. Further, Andersson et al. found that phase separation into pure oxides were favored over the formation of doped alumina for the investigated dopants. In this paper we use first principles and thermodynamical calculations to study the inclusion of $\mathrm{C}, \mathrm{Cl}, \mathrm{H}$ and $\mathrm{S}$. We start from the known precursor gases, their concentrations and the corundum crystal structure, and study the solubility of neutral and charged point defects in $\alpha-\mathrm{Al}_{2} \mathrm{O}_{3}$. We specifically apply different conditions to the heat of formation of the investigated defects to approximate more realistic thermodynamics in Chemical Vapor Deposition (CVD) and Physical Vapor Deposition (PVD).

\section{Computational Method}

The SSUB3 database [40] in Thermocalc [20], using the CALPHAD approach [41] was used to evaluate the species in the gas phase. More details of the 
method can be found in our previous paper [8]. The ab initio modeling was performed in the software VASP [22] using the GGA-PBE [35] functional and the PAW method [9]. The molecules were modeled in boxes of 20x20x20 $\AA$ in order to avoid interactions between the molecules in each supercell. A Gamma point sampling and first order Methfessel-Paxton smearing was used for the optimization of the molecules. For the modeling of defects in the solid oxide all neutral defects were first run with spin polarized calculations and if there was no magnetic moment present, latter calculations were non-spin polarized. For all geometry optimizations an energy cutoff of 800 $\mathrm{eV}$ was used, since the convergence of cutoff energy is slow already for the pure $\alpha-\mathrm{Al}_{2} \mathrm{O}_{3}$. The tolerance for energy convergence was set to $1 \cdot 10^{-6} \mathrm{eV}$. A k-point mesh of $2 \times 2 \times 2$ k-points was used for the geometry optimizations and a mesh of $4 \times 4 \times 4$ k-points for the final electronic calculations, using the linear tetrahedron method. To investigate the accuracy of the rigid band shift used in this paper in order to correct for the erroneous DFT band gap, $\mathrm{G}_{0} \mathrm{~W}_{0}$-calculations were used in addition to DFT for the case of chlorine substituting oxygen. The GW approach improves the Hartree-Fock approximation and is based on the concept of screened Coloumb interaction [10]. It enables us to extract the quasi-particle eigenvalues (quasiparticle energies) and eigenfunctions (wavefunctions) which provide an improved description of empty states. In principle, the GW approach is able to describe features originating from single particle excitations. In this work we apply the commonly used GW approximation, where the self energy, $\Sigma$, which corresponds to the Hamiltonian operator in the mean field framework, is replaced by a $\delta$-function. The defect heat of formation was calculated within the combined $\mathrm{G}_{0} \mathrm{~W}_{0}$ and DFT-approach suggested by Bruneval et al. [10] and Rinke et al. [37].

\subsection{Crystal Structure}

The crystal structure of $\mathrm{Al}_{2} \mathrm{O}_{3}$ can either be described by a rhombohedral unit consisting of 10 atoms, $4 \mathrm{Al}$ and $6 \mathrm{O}$, which is the primitive unit cell (Fig. 1). Alternatively three of these units are connected giving the hexagonal cell of 30 atoms, whereof 12 are aluminum atoms and 18 are oxygen atoms.

In this work we have chosen the rhombohedral unit and constructed a $2 \times 2 \times 2$ supercell consisting of 80 atoms. Replacing, adding or removing one atom to create a defect in the supercell, corresponds to a concentration of $\approx 1.2$ at\%. The advantage of this unit cell is the slight difference in length between the a, b and c-axes, as compared to the long c-axis of the hexagonal unit cells. Large difference in length of the three axes may induce strong anisotropic interactions between the defects and their mirror images in the 
neighboring supercells. The choice of the rhombohedral unit cell decreases these interactions and thereby the error due to the slow decay of the electrostatic potential of a defect (neutral or charged)is reduced. There are corrections for this unphysical interaction, such as the Multipole (Makov Payne) [32] correction. Although this kind of correction is often used, their accuracy has been strongly questioned, with several studies suggesting that they are not reliable enough for regular use[11]. Thus, we have not considered this correction.

\subsection{Models of experimental synthesis conditions}

To access the full thermodynamics of a system with defect, the Gibbs Energy of the system needs to be calculated

$$
G(T)=H(T)-T \cdot S(T)=U+U(T)-T \cdot S(T)+P(T) \cdot V(T)
$$

Where $\mathrm{U}$ is the internal energy, $\mathrm{T}$ is the temperature and $\mathrm{S}$ is the entropy. $\mathrm{P}$ is the applied pressure and $\mathrm{V}$ is the volume of the system.

In this work temperature and pressure effects have been neglected, such that the formation enthalpy $\mathrm{H}$ is replaced by the internal energy $\mathrm{U}$. Consequently throughout this work, the term defect formation energy will be used with notation $\mathrm{H}_{f}$ when we refer to the internal energy required to form the defect.

To calculate defect formation energy we have used two different approaches. First, we have applied the approach described by, amongst others, Persson et al. [36] and C.G. Van de Walle et al. [13]. Here the defect formation energy is defined as

$$
\begin{array}{r}
\Delta H_{f}\left(D^{q}, E_{F}, \mu\right)=\left[E_{T}\left(D^{q}\right)-E_{T}\right] \\
-\sum_{\alpha} n_{\alpha}\left(\mu_{\alpha}^{\text {elem }}+\Delta \mu_{\alpha}\right)+q\left(\Delta E_{F}+E_{V}\right) .
\end{array}
$$

Where $\mathrm{D}^{q}$ is the defect, $\mathrm{D}$, with charge $\mathrm{q}, \mathrm{E}_{T}\left(\mathrm{D}_{q}\right)$ and $\mathrm{E}_{T}$, are the total energies of the supercells with and without defect, respectively. In the third term, $\mathrm{n}_{\alpha}$ is the number of atoms added $\left(\mathrm{n}_{\alpha} \geq 0\right)$ or removed $\left(\mathrm{n}_{\alpha} \leq 0\right)$ to create the defect while $\mu^{\alpha}=\mu_{\alpha}^{\text {elem }}+\Delta \mu_{\alpha}$ is the chemical potential of the reservoir containing $\alpha$-atoms $(\alpha=\mathrm{Al}, \mathrm{O}$ and $\mathrm{X}$, where $\mathrm{X}=\mathrm{C}, \mathrm{Cl}, \mathrm{H}$ or $\mathrm{S}) . \mu_{\alpha}^{\text {element }}$ is the standard reference state of each element, i,e, fcc-Al(s), $\mathrm{O}_{2}(\mathrm{~g}), \mathrm{Cl}_{2}, \mathrm{H}_{2}$, $\mathrm{S}_{8}(\mathrm{~s})$. For $\mathrm{C}$, graphite is choosen as reference state and is calculated from 
the DFT total energy of diamond, adding the experimental energy difference between diamond and graphite. In order to keep thermodynamic equilibrium between the components, $\mathrm{Al}$ and $\mathrm{O}$, and the target compound of our study, $\mathrm{Al}_{2} \mathrm{O}_{3}$, the relation $3 \Delta \mu_{O}+2 \Delta \mu_{A l}=\Delta \mathrm{H}_{f}\left(\mathrm{Al}_{2} \mathrm{O}_{3}\right)$ should be satisfied, where $\Delta \mathrm{H}_{f}\left(\mathrm{Al}_{2} \mathrm{O}_{3}\right)$ is the calculated formation energy of $\alpha$-aluminum oxide. Thus, the atomic chemical potentials can be chosen between the limits of O-rich [Al-poor, $\Delta \mu_{O}=0$ and $\Delta \mu_{A l}=\Delta \mathrm{H}_{f}\left(\mathrm{Al}_{2} \mathrm{O}_{3}\right)$ ] and O-poor [Al-rich, $\Delta \mu_{A l}=$ 0 and $\left.\Delta \mu_{O}=\Delta \mathrm{H}_{f}\left(\mathrm{Al}_{2} \mathrm{O}_{3}\right)\right]$ conditions. These conditions will be denoted $H_{f}^{O R I C H}$ and $H_{f}^{O P O O R}$.

The final term takes the contribution from electron chemical potential into account and will be discussed in detail in the next section. For neutral defects, this term will be zero. Here, $\mathrm{q}$ is the charge of the defect, $\Delta \mathrm{E}_{F}$ is the change in Fermi energy and $E_{V}$ is the Valence Band (VB) maximum.The electronic properties of the large band gap insulator $\mathrm{Al}_{2} \mathrm{O}_{3}$ will be altered by the defects addressed in this paper. Therefore, the Fermi energy will be a function of the introduced defects.

This approach may be applied to, at a very simplified level, study conditions of some common types of Physical Vapor Deposition (PVD) such as Cathodic Arc deposition and magnetron sputtering. In these methods a metallic target is often used, from which atoms/ions are extracted either by the striking of a high current, low voltage arc (cathodic arc deposition) [4] or by the ejection of target material as ions bombard onto the target surface (magnetron sputtering) [34]. In both Cathodic Arc deposition and magnetron sputtering, a reactive gas such as oxygen gas may be used to form metal oxide as the gas reacts with the target material. We therefore refer to the deposition conditions as $P V D$-conditions.

In the second approach, the reactants and products of a typical Chemical Vapor Deposition (CVD) of $\mathrm{Al}_{2} \mathrm{O}_{3}$ were used as source of the carbon, chlorine, hydrogen and sulfur impurities. We denote this enthalpy of formation as $\Delta \mathrm{H}_{f}^{M o l}$ and refer to the deposition conditions as CVD-conditions. The choice of reference states in a CVD process is difficult since there are sometimes many sources of the same atom. As an example, water as well as hydrogen chloride, or both, could in principle correspond to the hydrogen chemical potential. Therefore the choice has to be based upon some prior knowledge of which reactions take place in the CVD-reactor. This approach will be described in more detail in the next section.

Finally, the band gap has been corrected by a rigid shift to the experimental band gap. The defect states interacting with the $\mathrm{CB}$ (only chlorine) in this case were corrected with a linear shift up in energy with the $\mathrm{CB}$, scaled with the number of states interacting. 


$$
E_{B g}=n \cdot\left(E_{g}^{T h e o}-E_{g}^{E x p}\right)
$$

Where $\mathrm{E}_{B g}$ is the correction term for the band gap, $\mathrm{E}_{g}^{\text {Theo }}$ is the theoretical value and $\mathrm{E}_{g}^{E x p}$ is the experimental value of the band gap.

\section{Results}

\subsection{Gas phase simulations}

Gas flows used in a current CVD process were converted into molar contents of each gas species, using the ideal gas law as a first approximation. The molar contents of each species was used as input in an equilibrium calculation at a temperature of $1283 \mathrm{~K}$ and a total pressure of $5500 \mathrm{~Pa}$ (typical for an industrial CVD-process (Table 1). From this equilibrium calculation, we extracted the gas species resulting from this reaction and which are thermodynamically stable at the modeled conditions $\left(\mathrm{H}_{2}, \mathrm{CO}, \mathrm{H}_{2} \mathrm{O}, \mathrm{HCl}, \mathrm{AlCl}_{2} \mathrm{OH}\right.$, $\mathrm{AlCl}_{3}, \mathrm{H}_{2} \mathrm{~S}$ and $\mathrm{CO}_{2}$ ). More details on the equilibrium calculation can be found in our previous paper [8]. The species with highest concentration were modeled with first principles calculations. $\mathrm{AlCl}_{2} \mathrm{OH}$ and $\mathrm{AlCl}_{3}$ had very similar heat of formation (-613 and $-699 \mathrm{~kJ} / \mathrm{mol}$ ) and therefore only $\mathrm{AlCl}_{3}$ was included as a reference state.

The products with highest molar contents were then modeled ab initio. It was then assumed that the gas phase has the time to reach local equilibrium during the deposition. This is a rough approximation, since the composition close to the surface of the substrate can be far from equilibrium. We started the study by verifying the agreement between the heat of formation calculated from first principles and measured data (Table 2). The modeling of finite molecules using a periodic approach as that applied in this work, is not optimal, but was required since this method is the most suitable for the solid state modeling. We find that the deviation of our calculated values from the measured data is $5 \%$ or less, which should be considered satisfactory for these kind of systems.

On the basis of the stable species found in our equilibrium calculation the reactions involving each defect as well as the reactions competing with dissolution of the defect in $\mathrm{Al}_{2} \mathrm{O}_{3}$ could be decided. The assumed carbon source was $\mathrm{CO}$ formed from $\mathrm{CO}_{2}$ precursor gas during the deposition process. These reactions are presented in Table 3. 


\subsection{Solid state modeling}

\subsubsection{Defect electronic structure}

First, the cell parameters of the rhombohedral primitive cell of $\alpha-\mathrm{Al}_{2} \mathrm{O}_{3}$ calculated from first principles was compared to previous experimental and theoretical values (Table 4). The agreement with previous work was satisfactory, with only a very slight underestimation of the cellparameter a within the third digit compared to Lindström et al[44]. Since intrinsic defect concentration (originating from $\mathrm{Al}_{2} \mathrm{O}_{3}$ ) can be enhanced by the inclusion of extrinsic defects $(\mathrm{C}, \mathrm{Cl}, \mathrm{H}, \mathrm{S})$ and vice versa, we studied the most common intrinsic defects in $\alpha-\mathrm{Al}_{2} \mathrm{O}_{3}$. T hese are the oxygen vacancy, $\mathrm{V}_{O}$, oxygen interstitial, $\mathrm{O}_{I}$, aluminum vacancy, $\mathrm{V}_{A l}$ and the aluminum interstitial, $\mathrm{Al}_{I}$. We compared the positions of the intrinsic defect states in the band gap to earlier theoretic $\mathrm{al}$ and experimental studies as is displayed in Fig. 2 a-d. In agreement with previous results, $\mathrm{O}_{I}$ and $\mathrm{V}_{A l}$ are shallow acceptors, whereas, $\mathrm{Al}_{I}$ introduces states in the Conduction Band (CB). $\mathrm{V}_{O}$ displays deep defect states, well known from photoluminescence (PL) and absorption measurements $[15,1]$. We will return to the intrinsic defects as their heat of formation is studied as a function of Fermi energy.

First, the substitutional solution of carbon, $\mathrm{C}_{O}$, chlorine, $\mathrm{Cl}_{O}$, hydrogen, $\mathrm{H}_{O}$ and sulfur, $\mathrm{S}_{O}$ in $\alpha-\mathrm{Al}_{2} \mathrm{O}_{3}$ was examined. Only the oxygen position (there is only one unique position in $\alpha-\mathrm{Al}_{2} \mathrm{O}_{3}$ ) was considered for substitution, since all the investigated defects are non-metals and form compounds with aluminum. Substitution of aluminum atoms were not considered, since this is expected to be highly unlikely, (substitution of an electron donor by an electron acceptor) due to the ionic nature of $\mathrm{Al}_{2} \mathrm{O}_{3}$. In Fig. 2 e-h the density of states of four neutral substitutional defects is displayed. In the case of carbon there are two occupied and two unoccupied spin polarized states. Carbon appears to be an acceptor defect since the Fermi energy, $\mathrm{E}_{F}$, is pinned close to the (VB). For chlorine, $\mathrm{E}_{f}$ is instead in the $\mathrm{CB}$. This indicates that chlorine is a donor defect. Hydrogen induces one occupied defect state close to the CB. This would suggest hydrogen as a donor defect. Finally sulfur pins $\mathrm{E}_{f}$ on one of the three occupied defect states which appear close to the $\mathrm{VB}$, implying that sulfur is an acceptor defect.

It is important not only to study the substitution of oxygen by carbon, chlorine, hydrogen and sulfur, but also to investigate possible interstitial positions. Especially hydrogen and carbon are small ions when they are in their positive charge states and may readily diffuse in $\mathrm{Al}_{2} \mathrm{O}_{3}$. Again, we studied density of states of the interstitial defects, Fig. 2 i-l. The interstitial defects are denoted with an index $I$. Carbon again introduces both occupied 
and unoccupied deep states, resembling the carbon substitutional defect. Chlorine instead changes from being a shallow donor and introduces deep occupied states below the center of the band gap. The same behavior seems to be true for hydrogen, which introduces deep states in the gap. The previously occupied shallow states of sulfur separate and move to higher energies, one of them turning unoccupied. $\mathrm{E}_{F}$ pins to one of the intermediate states. Clearly the substitutional and interstitial defects alter the electronic structure of $\mathrm{Al}_{2} \mathrm{O}_{3}$. The question is now whether they are stable enough to form at equilibrium conditions.

\subsubsection{Neutral defect energetics}

In Fig. 3, the heat of formation of the neutral intrinsic and extrinsic defects, calculated at the three different experimental conditions as previously described, are displayed. The calculated values are also tabelled in Table 5. First, we would like to point out which defects will be dependent on the oxygen gas pressure. These defects are the aluminum interstitial, $\mathrm{Al}_{I}$, the aluminum vacancy, $\mathrm{V}_{A l}$, the oxygen vacancy, $\mathrm{V}_{O}$, the oxygen interstitial, $\mathrm{O}_{I}$, and the impurities replacing oxygen which we denote as $\mathrm{Cl}_{O}$ (chlorine), $\mathrm{S}_{O}$ (sulfur), $\mathrm{C}_{O}$ (carbon) and $\mathrm{H}_{O}$ (hydrogen). In the case of the interstitial impurities $\mathrm{Cl}_{I}$ (chlorine), $\mathrm{S}_{I}$ (sulfur), $\mathrm{C}_{I}$ (carbon) and $\mathrm{H}_{I}$ (hydrogen), we assume that they are independent of oxygen gas pressure (since they do not replace any oxygen on the oxygen lattice), and their heat of formation are subsequently identical at oxygen poor and rich conditions. This is however a simplification, since some of the defects were formed from oxygen containing species in the gas phase and will therefore be indirectly dependent on the oxygen gas pressure.

Our first conclusion is that the heat of formation from the CVD gas phase lies in between the extremum conditions of high and low oxygen gas pressure. This is interesting, since it puts the simulated CVD experimental conditions in between the possible conditions of the simulated PVD conditions. From the calculated oxygen-poor conditions, the driving force to form oxygen vacancies, $\mathrm{V}_{O}$ hydrogen interstitials, $\mathrm{H}_{I}$, chlorine interstitial, $\mathrm{Cl}_{I}$ and hydrogen and sulfur substituting oxygen, $\mathrm{H}_{O}$ and $\mathrm{S}_{O}$, will increase (defects with formation energies less than $2.5 \mathrm{eV}$ are marked by a dashed line in Fig. ??. This implies that there may be some non-negligible concentration of $\mathrm{V}_{O}, \mathrm{H}_{I}$ and $\mathrm{S}_{O}$ in $\alpha-\mathrm{Al}_{2} \mathrm{O}_{3}$ in PVD of $\alpha-\mathrm{Al}_{2} \mathrm{O}_{3}$ at low oxygen partial pressures during the deposition. However, in PVD of oxides, the conditions are most likely close to oxygen rich if one wants to achieve stoichiometric oxides. We conclude that independent of reference states, we find similar trends for all investi- 
gated dopants and intrinsic defects. This reassures us that our method of calculating both solids and molecules within the DFT approach gives qualitatively reasonable results. As is seen in Fig. 3, the lowest energy neutral defects (we do not consider oxygen poor conditions) are $\mathrm{H}_{I}$ and $\mathrm{Cl}_{I}$. They present heats of formation of 1.67 and $1.79 \mathrm{eV}$ at PVD-conditions and 2.91 and $2.90 \mathrm{eV}$ as they form in equilibrium with molecules in gas phase. Another important result is the preference for sulfur to replace oxygen, whereas the sulfur interstitial is high in energy. The sulfur substitutional defect, $\mathrm{S}_{O}$, may even form spontaneously (negative defect heat of formation) at the modeled oxygen poor PVD-conditions. In CVD of $\alpha$ - $\mathrm{Al}_{2} \mathrm{O}_{3}$ however, where $\mathrm{H}_{2} \mathrm{~S}$ is used as a catalyst, sulfur would not be solved in $\alpha-\mathrm{Al}_{2} \mathrm{O}_{3}$ according to the present study.

We have compared our calculated heat of formation for the oxygen interstitial, which we find to be in a singlet state with $0 \mu \mathrm{B}$ magnetization with previously calculated values by Sokol et al. [2]. Our calculated value of 5.56 $\mathrm{eV} / \mathrm{f}$.u. is in excellent agreement with the calculated heat of formation by Sokol et al., $5.38 \mathrm{eV}$ (triplet state) and 5.58 (singlet state).

\subsubsection{Charged defect energetics}

It is of great importance to take the ionicity of $\mathrm{Al}_{2} \mathrm{O}_{3}$ into account, by assuming that not only neutral defects may form. Charged defects commonly form in ionic-like oxides and are compensated by intrinsic defects or by carriers. In large band gap oxides such as $\mathrm{Al}_{2} \mathrm{O}_{3}$ and $\mathrm{ZrO}_{2}$, ionic conduction is high, but electronic conduction is low. Thus, in general, there needs to be sufficient amount of intrinsic defects in order to compensate the charged defects and to solve in the oxide. From the analysis of the neutral defects, we found the hydrogen and chlorine interstitial to be lowest in energy. If we instead study the formation energy as a function of the Fermi energy, adding the last term of Eq. 2, the picture changes.

First we compare our results for the oxygen vacancy and interstitial with previous theory (Fig. 4). Our calculated charge transitions with the PBE functional lie in between those calculated by LDA and the hybrid functional HSE for $\gamma-\mathrm{Al}_{2} \mathrm{O}_{3}$ by Weber et al.. Also, the calculated heat of formation is in good agreement with Weber et al. [45].

In Fig. 5-6 the formation energies from molecules in the gas phase of a typical CVD-process are displayed. The defects are denoted with superscript $\mathrm{Mol}$, and formation energies from standard reference states are denoted with superscript OPOOR (oxygen poor conditions) and ORICH (oxygen rich conditions). For interstitial defects, there is no superscript for the formation 
energy from standard reference states, since these defects are independent of oxygen partial pressure.

Then we continue with the hydrogen interstitial, $\mathrm{H}_{I}$, and hydrogen substituting oxygen, $\mathrm{H}_{O}$ (Fig. 5 a,b). $\mathrm{H}_{I}$ has been extensively studied by Walle et al. [14] and is found to be amphotheric, i.e. that it can gain both the negative and positive charge state, in a large number of semiconductors and oxides. This is also what we find for both $\mathrm{H}_{I}$ and $\mathrm{H}_{O}$. The very small range in which the neutral state is stable may be considered as within the error bars of the calculation (Fig. 5).

As we study the carbon interstitial, $\mathrm{C}_{I}$, Fig. $5 \mathrm{c}$, we find surprisingly that it is also of amphoteric character. This is interesting, since carbon has previously been found to passivate defects in $\alpha-\mathrm{Al}_{2} \mathrm{O}_{3}$. Passivation means, that the passivating defect will interact with other defects, often eliminating their electrical activity, but stabilizing the defect in its charge state. The heat of formation of carbon substituting for oxygen is displayed in Fig. 5 d. Apparently, $\mathrm{C}_{O}$ is stable in the -2 charge state throughout the band gap at the simulated CVD-conditions and through most of the band gap at oxygen rich conditions. This is an unexpected result since it suggests spontaneous solution of carbon in $\alpha-\mathrm{Al}_{2} \mathrm{O}_{3}$ at the investigated conditions and at a concentration of 1.2 at\% carbon. Most likely, the formation of additional competing carbon containing phases need to be considered in the calculations to achieve a trustable prediction of the carbon solubility. $\mathrm{Al}_{4} \mathrm{C}_{3}, \mathrm{Al}_{2} \mathrm{OC}$ and $\mathrm{Al}_{4} \mathrm{O}_{4} \mathrm{C}$ are according to Lihrmann et al. [26] stable at low enough partial pressures of $\mathrm{CO}$ and at high enough temperatures [25].

The chlorine interstitial maintains its neutral charge state through most of the band gap and decays into the -2 charge state at about $7.5 \mathrm{eV}$ (Fig. 6 a). As the band gap correction is applied, the -2 charge state is no longer stable and instead there is a +1 to neutral transition at $7.5 \mathrm{eV}$. When replacing oxygen by chlorine, chlorine gains the +1 charge state, since it may accommodate one electron less than oxygen $(6 \mathrm{~b})$. At around $6 \mathrm{eV}$ the +1 charge state decays into the -2 charge state. This transition is replaced by a +1 to neutral charge state transition as the band gap correction is applied, since both electrons of the -2 charge state interact with the conduction band. The transition from the neutral to -2 charge state just below the experimental band gap is considered negligible.

Sulfur at an interstitial position also seems to display amphotheric properties (Fig. 6 c). However it is higher in energy than both $\mathrm{H}_{I}$ and $\mathrm{C}_{I}$ and is not likely to form. As sulfur replaces oxygen, Fig. $6 \mathrm{~d}$, the neutral charge state of sulfur is stable up to just below $6 \mathrm{eV}$, where it gains the -2 charge state. 
Cation-anion compensation is more likely than anion-anion compensation, since $\mathrm{Al}_{2} \mathrm{O}_{3}$ is mainly ionic and since compensation requires charge transfer from donor to acceptor defects. We therefore also considered the compensation amongst the extrinsic defects by comparing each of them in the same heat of formation versus Fermi energy diagram. It is found that the amphotheric defects will not compensate any of the non-amphotheric defects (no crossing of defect heat of formation curves throughout the band gap of $\alpha-\mathrm{Al}_{2} \mathrm{O}_{3}$ at CVD-conditions. This is expected since these these defects should rather compete for sites on the anion lattice (or interstitial sites) due to the ionic character of $\alpha-\mathrm{Al}_{2} \mathrm{O}_{3}$.

The compensation of extrinsic defects by intrinsic defects was investigated by comparing their heat of formation as a function of Fermi Energy. Out of carbon, chlorine, hydrogen and sulfur interstitial and substitutional defects, only carbon and chlorine substituting oxygen can be compensated by intrinsic defects. Carbon substitution of oxygen is, as previously pointed out, found to be energetically favored under the simulated CVD-conditions at carbon contents of 1.2 at\%. However, care needs to be taken when choosing the possible competing carbon-containing phases. Under the modeled CVD-conditions, compensation of $\mathrm{C}_{O}$ by oxygen vacancies, $\mathrm{V}_{O}$ takes place at $-1.33 \mathrm{eV}(-128 \mathrm{~kJ} / \mathrm{mol})$ (Fig. 7. Under the modeled PVD conditions, oxygen vacancies may compensate for carbon substituting oxygen at an energy of $1.14(110 \mathrm{~kJ} / \mathrm{mol})$. Chlorine replacing oxygen, $\mathrm{Cl}_{O}$, is compensated by interstitial oxygen, $\mathrm{O}_{I}$ at around $3.78 \mathrm{eV}(365 \mathrm{~kJ} / \mathrm{mol})$ under the simulated CVD conditions (Fig. 8. This is a too high energy to obtain in a CVDprocess and therefore charge compensation between substitutional $\mathrm{Cl}_{O}$ and $\mathrm{O}_{I}$ at interstitial sites will most likely not take place. At the simulated PVD conditions, an energy of $3.48 \mathrm{eV}(336 \mathrm{~kJ} / \mathrm{mol})$ is needed for this defect pair to form. These energy are too high to achieve in a CVD-process but may be overcome in PVD such as Cathodic Arc Deposition, or possibly in plasma enhanced (PE) CVD. In both these techniques, large amounts of energy is provided by, in the first case, a high current, low voltage arc, and in the second, a plasma consisting of a significant percentage of unstable ions or molecules. These off-equilibrium factors drives the formation of metastable phases and the capturing of defect states otherwise not feasible at equilibrium conditions. 


\subsubsection{Effect of supercell size on defect formation energy}

The choice of supercell size is of major importance to calculate energetics of defects at the dilute limit and its influence on defect formation energy has been shown by amongst others [11] et al. Therefore the influence of cell size on the defect formation energy was investigated for three different cell sizes; 10 atoms (primitive cell), 80 atoms (2x2x2 supercell) and 270 atoms (3x3x3 supercell). In Table 6 , the calculated formation energies of a neutral and +2 charged oxygen vacancy for each supercell size are displayed. From Table 6 it is seen that the heat of formation of the oxygen vacancy has not converged for such a high concentration as 1 vacancy/10 atoms which is much expected. For the 80 atoms supercell, the energy is converged to $1 \mathrm{meV}$ for the charged oxygen vacancy and to $100 \mathrm{meV}$ for the neutral vacancy compared to the 270 atoms supercell. The difference of $100 \mathrm{meV}$ is somewhat large, but would not change our main conclusions from this work.

\subsubsection{Accuracy control of the rigid band shift by the $\mathrm{G}_{0} \mathrm{~W}_{0}$ method}

In order to test whether the rigid band shift may accurately determine the defect level positions in the gap, the $\mathrm{G}_{0} \mathrm{~W}_{0}$ method was applied to calculate the DOS and positions of the $\mathrm{Cl}_{O}+1$ and neutral charge states (Fig. 9). Comparing DOS calculated by $\mathrm{G}_{0} \mathrm{~W}_{0}$ and DFT, there is no change in spectral features, but merely a rigid shift of the CB to higher energy. Studying the defect heat of formation as a function of Fermi energy, it is seen that $G_{0} W_{0}$ predicts the transition from +1 to 0 charge state of chlorine takes place at an energy slightly lower than the CB whereas DFT predicts this transition just at the CB. Therefore the rigid band shift seems to give a qualitatively good estimation of the charge state transition.

\section{Conclusions}

The hydrogen interstitial, $\mathrm{H}_{I}$ and the chlorine interstitial, $\mathrm{Cl}_{I}$ display the lowest formation energy amongst the investigated neutral defects at oxygen rich conditions and at CVD-conditions, where gas phase molecules have been used as reference states. The calculation of defect heat of formation from CVD reference species seems to be reliable, giving values in between oxygen poor and oxygen rich conditions. Our calculations suggest that sulfur from the catalysing agent $\mathrm{H}_{2} \mathrm{~S}$ will not solve in $\alpha-\mathrm{Al}_{2} \mathrm{O}_{3}$ during the deposition of $\alpha-\mathrm{Al}_{2} \mathrm{O}_{3}$ by CVD. It is found that not only $\mathrm{H}_{I}$ displays amphotheric properties in $\alpha-\mathrm{Al}_{2} \mathrm{O}_{3}$, but also $\mathrm{H}_{O}, \mathrm{C}_{I}$ and $\mathrm{S}_{I}$. None of the substitutional or interstitial anion defects will compensate at CVD-conditions. Cation-anion 
compensation is more likely than anion-anion compensation, since $\mathrm{Al}_{2} \mathrm{O}_{3}$ is mainly ionic and since compensation requires charge transfer from donor to acceptor defects. Carbon substitution of oxygen is found to be energetically favored under CVD-conditions and may be compensated by $\mathrm{V}_{O}$ at an energy of $-128 \mathrm{~kJ} / \mathrm{mol}$. However, care needs to be taken when choosing the possible competing carbon-containing phases. $\mathrm{C}_{O}$ may be compensated by $\mathrm{V}_{O}$ at an energy of $110 \mathrm{~kJ} / \mathrm{mol}$ when formed from standard reference states of the elements, $\mathrm{Cl}_{2}$, fcc-Al and $\mathrm{O}_{2}$. Chlorine replacing oxygen, $\mathrm{Cl}_{O}$ is compensated by interstitial oxygen at $336 \mathrm{~kJ} / \mathrm{mol}$ when formed from standard reference states and at $365 \mathrm{~kJ} / \mathrm{mol}$ at CVD-conditions. These energies are rather high and solubility of $\mathrm{Cl}$ is therefore predicted unlikely when depositing $\alpha-\mathrm{Al}_{2} \mathrm{O}_{3}$ by CVD. Chlorine solubility in $\alpha-\mathrm{Al}_{2} \mathrm{O}_{3}$ has only been previously demonstrated when deposited by plasma enhanced-CVD[18].

\section{Acknowledgement}

We would like to acknowledge the Swedish Research Council (VR) for financial supports. Resources of the Swedish National Infrastructure for Computing (SNIC), National Supercomputer Center (NSC) and the Uppsala Multidisciplinary Center for Advanced Computational Science (UPPMAX) are also gratefully acknowledged. 
Table 1: The gas flows in sscm and $\mathrm{l} / \mathrm{h}$ for a typical CVD of $\alpha-\mathrm{Al}_{2} \mathrm{O}_{3}$

\begin{tabular}{ccc}
\hline \hline Species & Gas flow (sscm) & Gas flow $(\mathrm{l} / \mathrm{h})$ \\
\hline $\mathrm{H}_{2}$ & 950 & 3420 \\
$\mathrm{HCl}$ & 31.7 & 114 \\
$\mathrm{CO}_{2}$ & 50.0 & 180 \\
$\mathrm{H}_{2} \mathrm{~S}$ & 3.83 & 13.8 \\
$\mathrm{AlCl}_{3}$ & 12.5 & 45 \\
\hline \hline
\end{tabular}

Table 2: Heat of formation at $0 \mathrm{~K}$ compared with experimental data and with previous theoretical work. The value marked with $\dagger$ is referenced to the atomic, not molecular species, i.e. $\mathrm{H}(\mathrm{g})$ instead of $\mathrm{H}_{2}(\mathrm{~g})$, in order to compare with values from the SSUB3 database, where the Gibbs energy of standard reference states are set to 0 .

\begin{tabular}{|c|c|c|c|c|c|c|}
\hline "Molecule & $\begin{array}{c}\mathrm{H}_{f}(\mathrm{~kJ} / \mathrm{mol}) \\
{[\text { This work }]}\end{array}$ & [40] & [6] & Exp. [23] & [23] & {$[17]$} \\
\hline Diamond & -878 & & & & & \\
\hline $\mathrm{Al}(\mathrm{fcc})$ & -371 & & & & & \\
\hline $\mathrm{H}_{2}$ & -439 & & & -458 & -438 & -456 \\
\hline $\mathrm{O}_{2}$ & -566 & & & -505 & -602 & -599 \\
\hline $\mathrm{S}_{2}$ & -506 & & -554 & & & \\
\hline $\mathrm{Cl}_{2}$ & -284 & & -242 & -243 & -273 & \\
\hline $\mathrm{H}_{2} \mathrm{O}$ & -965 & & & -972 & -981 & \\
\hline $\mathrm{H}_{2} \mathrm{~S}$ & -770 & & -734 & & & \\
\hline $\mathrm{HCl}$ & -449 & & -431 & & & \\
\hline $\mathrm{CO}$ & -1107 & & & & & \\
\hline $\mathrm{CO}_{2}$ & -1704 & & -1609 & & & \\
\hline $\mathrm{AlCl}_{3}$ & $-613 \dagger$ & -613 & & & & \\
\hline
\end{tabular}


Table 3: The different reactions for solution of defects into $\alpha-\mathrm{Al}_{2} \mathrm{O}_{3}$. Asterisk denotes the competing reactions, where no solution of defects takes place, for hydrogen, chlorine and carbon. Since sulfur is a catalyst, not taking part in any large extent in reactions where sulfur might be consumed [8], no competing reaction was considered.

\begin{tabular}{ccc}
\hline \hline Defect & Type Reaction & \\
\hline $\mathrm{H}$ & sub & $32 \mathrm{AlCl}_{3}+47 \mathrm{H}_{2} \mathrm{O}+\frac{3}{2} \mathrm{H}_{2} \rightarrow \mathrm{Al}_{32} \mathrm{O}_{47} \mathrm{H}+96 \mathrm{HCl}$ \\
$\mathrm{H}$ & int & $32 \mathrm{AlCl}_{3}+48 \mathrm{H}_{2} \mathrm{O}+\frac{1}{2} \mathrm{H}_{2} \rightarrow \mathrm{Al}_{32} \mathrm{O}_{48} \mathrm{H}+96 \mathrm{HCl}$ \\
$\mathrm{Cl}$ & sub & $32 \mathrm{AlCl}_{3}+47 \mathrm{H}_{2} \mathrm{O}+\frac{1}{2} \mathrm{H}_{2} \rightarrow \mathrm{Al}_{32} \mathrm{O}_{47} \mathrm{Cl}+95 \mathrm{HCl}$ \\
$\mathrm{Cl}$ & int & $32 \mathrm{AlCl}_{3}+48 \mathrm{H}_{2} \mathrm{O} \rightarrow \mathrm{Al}_{32} \mathrm{O}_{48} \mathrm{Cl}+95 \mathrm{HCl}+\frac{1}{2} \mathrm{H}_{2}$ \\
$\mathrm{C}$ & sub & $\mathrm{CO}+32 \mathrm{AlCl}_{3}+46 \mathrm{H}_{2} \mathrm{O}+2 \mathrm{H}_{2} \rightarrow \mathrm{Al}_{32} \mathrm{O}_{47} \mathrm{C}+96 \mathrm{HCl}$ \\
$\mathrm{C}$ & int & $\mathrm{CO}+32 \mathrm{AlCl}_{3}+47 \mathrm{H}_{2} \mathrm{O}+\mathrm{H}_{2} \rightarrow \mathrm{Al}_{32} \mathrm{O}_{48} \mathrm{C}+96 \mathrm{HCl}$ \\
$\mathrm{S}$ & sub & $\mathrm{H}_{2} \mathrm{~S}+32 \mathrm{AlCl}_{3}+47 \mathrm{H}_{2} \mathrm{O} \rightarrow \mathrm{Al}_{32} \mathrm{O}_{47} \mathrm{~S}+96 \mathrm{HCl}$ \\
$\mathrm{S}$ & int & $\mathrm{H}_{2} \mathrm{~S}+32 \mathrm{AlCl}_{3}+48 \mathrm{H}_{2} \mathrm{O} \rightarrow \mathrm{Al}_{32} \mathrm{O}_{48} \mathrm{~S}+96 \mathrm{HCl}$ \\
$\mathrm{H}, \mathrm{Cl} \mathrm{Cl}^{*}$ & - & $32 \mathrm{AlCl}_{3}+48 \mathrm{H}_{2} \mathrm{O} \rightarrow 16 \mathrm{Al}_{2} \mathrm{O}_{3}+96 \mathrm{HCl}$ \\
$\mathrm{C}^{*}$ & - & $32 \mathrm{AlCl}_{3}+19 \mathrm{H}_{2} \mathrm{O}+\mathrm{CO} \rightarrow 16 \mathrm{Al}_{2} \mathrm{O}_{3}+96 \mathrm{HCl}+\mathrm{CO}_{2}+\mathrm{H}_{2}$ \\
\hline
\end{tabular}

Table 4: The lattice parameters and Wyckoff positions of the primitive rhombohedral cell of $\alpha-\mathrm{Al}_{2} \mathrm{O}_{3}$.

\begin{tabular}{cccc}
\hline \hline Quantity & $\begin{array}{c}\text { PBE } \\
{[\text { This work }]}\end{array}$ & $\begin{array}{c}\text { PW91. } \\
{[46]}\end{array}$ & $\begin{array}{c}\text { Expt. } \\
{[24]}\end{array}$ \\
\hline $\mathrm{a}(\AA$ & 5.126 & 5.161 & 5.128 \\
\hline alpha $($ deg. $\mathrm{C})$ & 55.28 & 55.27 & 55.28 \\
\hline $\mathrm{w}(\mathrm{Al})$ & 0.352 & 0.352 & 0.352 \\
\hline $\mathrm{u}(\mathrm{O})$ & 0.556 & 0.556 & 0.556 \\
\hline $\mathrm{V}\left(\AA^{3}\right)$ & 84.8 & 84.8 & 84.8 \\
\hline \hline
\end{tabular}


Table 5: The calculated heat of formation of the investigated neutral defects in $\mathrm{eV} / \mathrm{f}$.u. Values displayed in parantheses are in $\mathrm{kJ} / \mathrm{mol}$. Values with asterix for oxygen interstitial are the energies calculated by Sokol et al.[2]. $\mathrm{Al}_{I^{-}}$

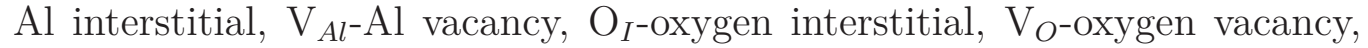
$\mathrm{C}_{I}$-carbon interstitial, $\mathrm{C}_{O}$-carbon replacing oxygen, $\mathrm{Cl}_{I}$-chlorine interstitial, $\mathrm{Cl}_{O}$-chlorine replacing oxygen, $\mathrm{H}_{I}$-hydrogen interstitial, $\mathrm{H}_{O}$-hydrogen replacing oxygen, $\mathrm{S}_{I^{-}}$sulfur interstitial, $\mathrm{S}_{O^{-}}$-sulfur replacing oxygen.

\begin{tabular}{|c|c|c|c|}
\hline Defect & $\mathrm{H}_{f}{ }^{m o l}[\mathrm{eV} /$ f.u. $(\mathrm{kJ} / \mathrm{mol})]$ & $\mathrm{H}_{f}{ }^{S E R}$ oxygen poor [eV/f.u.] & $\mathrm{H}_{f}{ }^{S E R}$ oxygen rich $[\mathrm{eV} /$ f.u. \\
\hline $\mathrm{Al}_{I}$ & $11.98(1155)$ & $9.29(896)$ & $16.74(1015)$ \\
\hline $\mathrm{V}_{A l}$ & $8.45(816)$ & $3.68(356)$ & $11.14(1075)$ \\
\hline $\mathrm{O}_{I}$ & $5.56,5.38^{*}, 5.68^{*}(536)$ & $8.00(772)$ & $3.03(282)$ \\
\hline $\mathrm{V}_{O}$ & $3.52(334)$ & $1.07(104)$ & $6.04(583)$ \\
\hline $\mathrm{C}_{I}$ & $7.73(745)$ & $9.51(917)$ & $9.51(917)$ \\
\hline $\mathrm{C}_{O}$ & $4.57(441)$ & $3.89(375)$ & $8.86(855)$ \\
\hline $\mathrm{Cl}_{I}$ & $2.91(280)$ & $1.67(161)$ & $1.67(161)$ \\
\hline $\mathrm{Cl}_{O}$ & $6.73(649)$ & $3.05(294)$ & $8.02(774)$ \\
\hline $\mathrm{H}_{I}$ & $2.90(280)$ & $1.79(173)$ & $1.79(173)$ \\
\hline $\mathrm{H}_{O}$ & $4.68(452)$ & $1.13(109)$ & $6.10(589)$ \\
\hline $\mathrm{S}_{I}$ & $11.03(1064)$ & $9.26(894)$ & $9.26(894)$ \\
\hline $\mathrm{S}_{O}$ & $3.40(328)$ & $-0.81(-78)$ & $4,16(401)$ \\
\hline
\end{tabular}

Table 6: The total energy of the defective and defect free structures for three different cell sizes. The heat of formation of one neutral and charged oxygen vacancy, $\mathrm{H}_{f}\left[\mathrm{~V}_{O}, \mathrm{q}=0\right]$ and $\mathrm{H}_{f}\left[\mathrm{~V}_{0}, \mathrm{q}=+2\right]$ was calculated from the expression: $\mathrm{H}_{f}\left[\mathrm{~V}_{0}, \mathrm{q}\right]=\mathrm{E}_{T}\left[\mathrm{~V}_{0}, \mathrm{q}\right]-\mathrm{E}_{T}[$ Perfect $]+1 / 2 \mathrm{E}_{T}\left[\mathrm{O}_{2}\right]$.

\begin{tabular}{|c|c|c|c|c|c|}
\hline Size & $\mathrm{E}_{T}\left[\mathrm{~V}_{0}, \mathrm{q}\right]$ & $\mathrm{E}_{T}\left[\mathrm{~V}_{O}, \mathrm{q}=+2\right]$ & $\mathrm{E}_{T}[$ Perfect $]$ & $\mathrm{H}_{f}\left[\mathrm{~V}_{O}, \mathrm{q}=0\right]$ & $\mathrm{H}_{f}\left[\mathrm{~V}_{0}, \mathrm{q}=+2\right]$ \\
\hline 1x1x1 (10 atoms) & -63.173 & -57.356 & -74.865 & 6.755 & 14.571 \\
\hline $2 \times 2 \times 2$ (80 atoms) & -587.514 & -563.897 & -599.251 & 6.800 & 8.804 \\
\hline $3 \times 3 \times 3$ (270 atoms) & -2010.749 & -1986.861 & -2022.485 & 6.900 & 8.803 \\
\hline
\end{tabular}




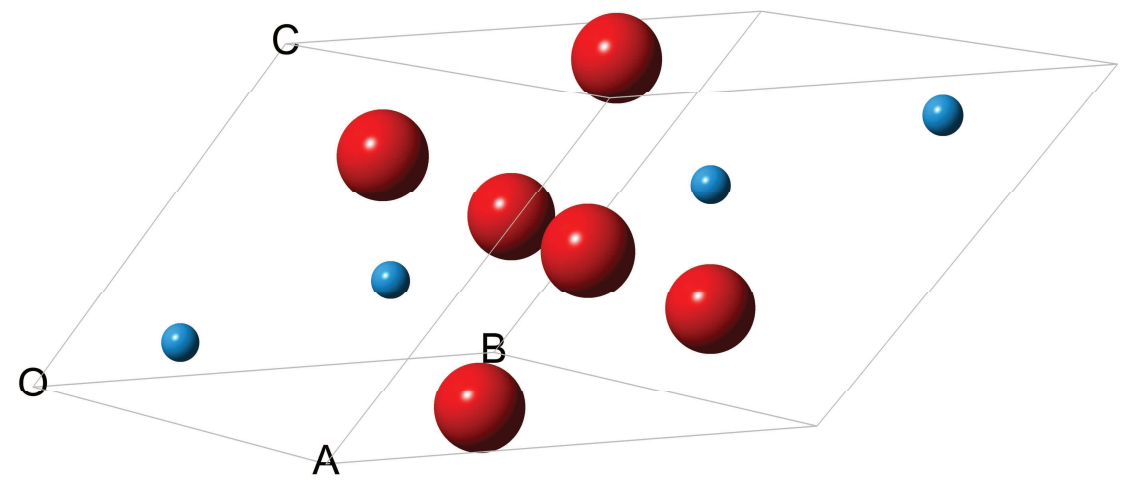

Figure 1: The primitive rhombohedral cell of $\alpha-\mathrm{Al}_{2} \mathrm{O}_{3}$. 


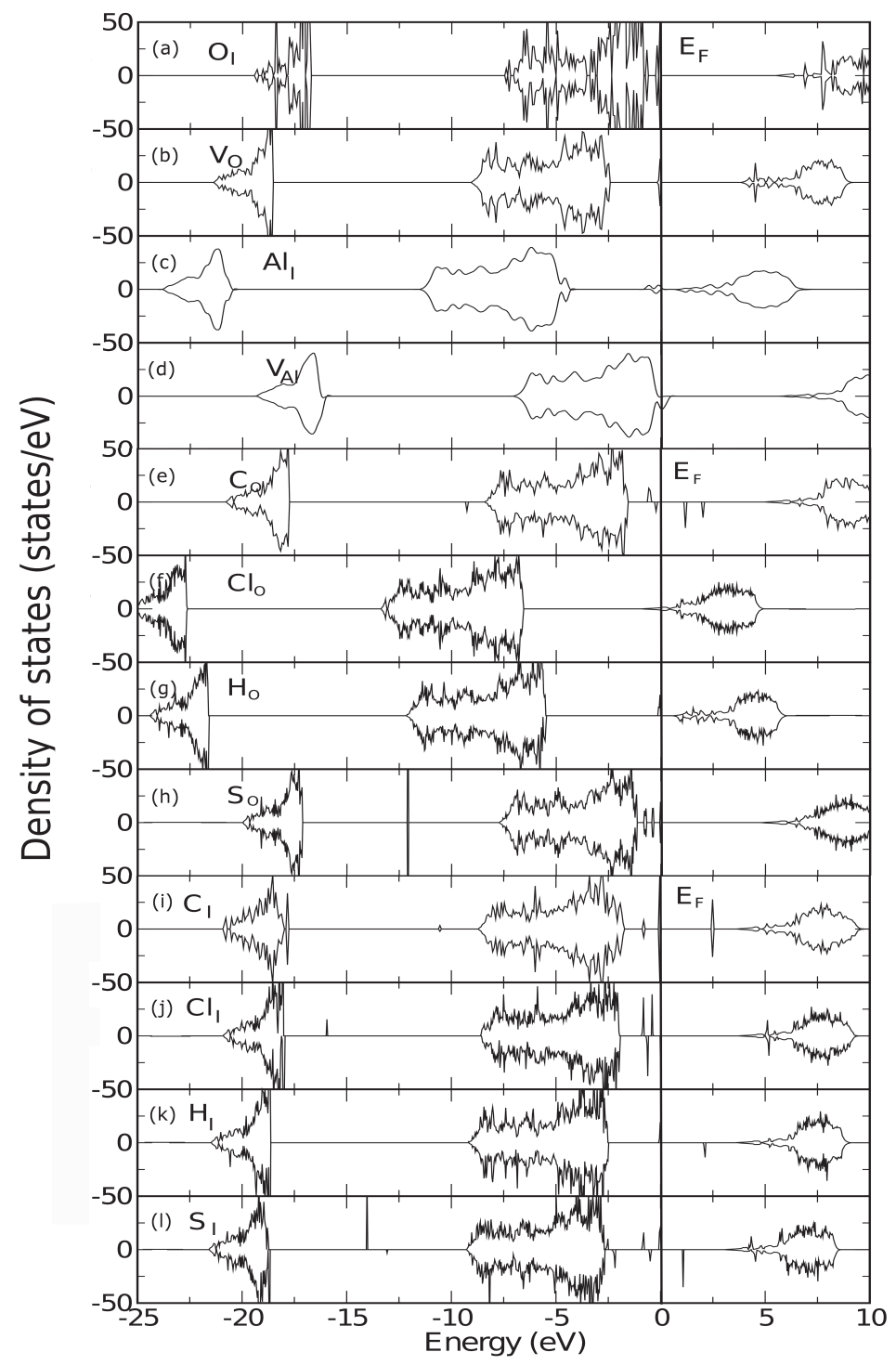

Figure 2: The density of states of the neutral intrinsic defects. (a) $\mathrm{O}_{I^{-}}$

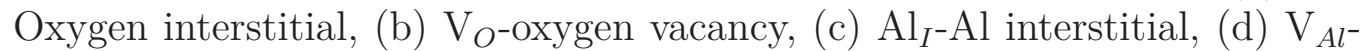
Al-vacancy (e) $\mathrm{C}_{O}$-Carbon replacing oxygen, (f) $\mathrm{Cl}_{O}$-Chlorine replacing oxygen, (g) $\mathrm{H}_{O}$-Hydrogen replacing oxygen, (h) $\mathrm{S}_{O^{-S u l f u r}}$ replacing oxygen, (i) $\mathrm{C}_{I^{-}}$Carbon interstitial, (j) $\mathrm{Cl}_{I^{-}}$Chlorine interstitial, (k) $\mathrm{H}_{I^{-}}$Hydrogen inter-

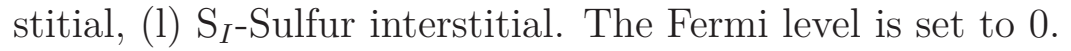




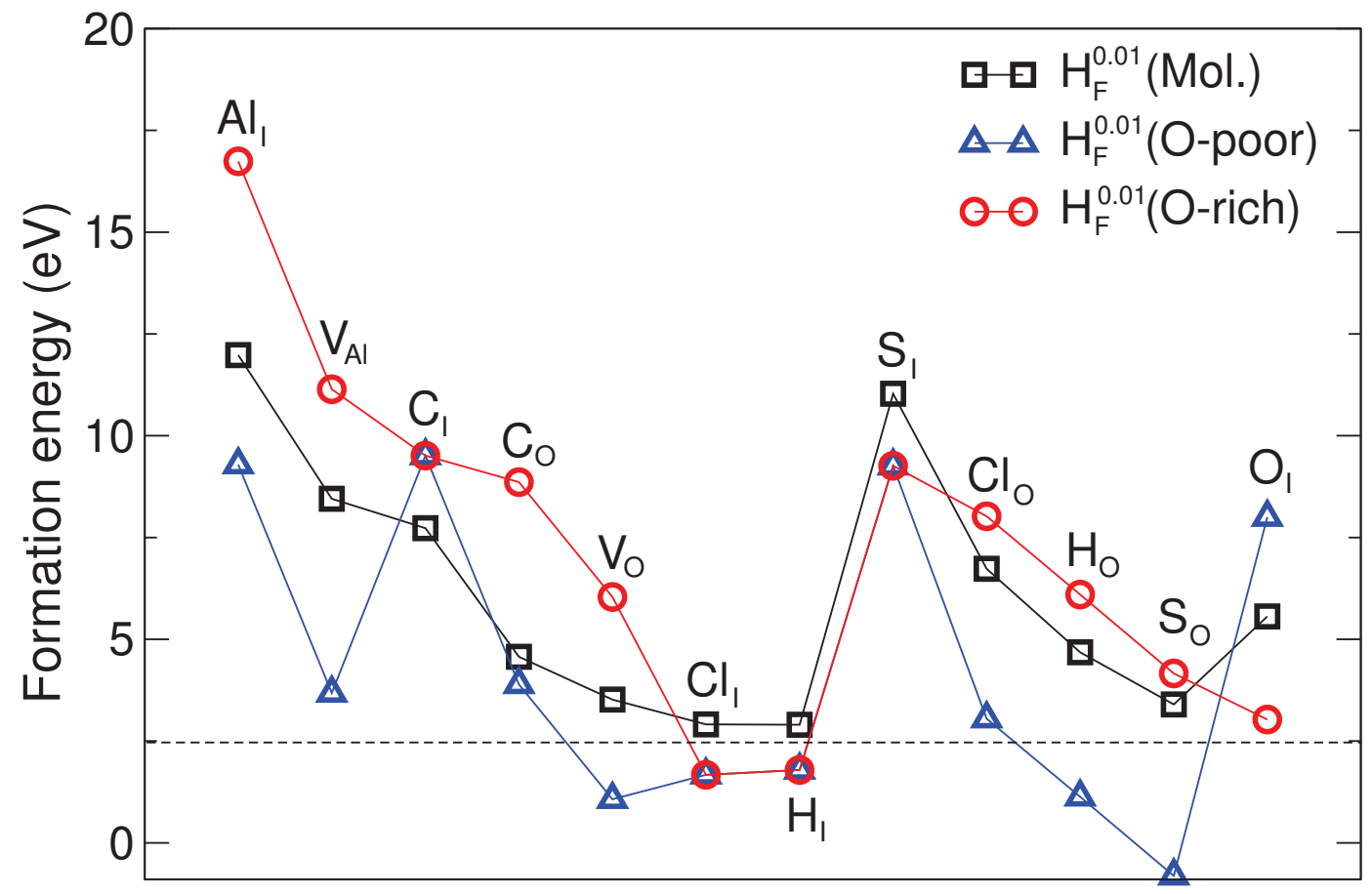

Figure 3: The formation energy of all neutral intrinsic and extrinsic defects calculated from two different approaches. $\mathrm{H}_{F}^{M o l}$ is calculated from molecules in the gas phase of a typical CVD process. $\mathrm{H}_{F}^{O-\text { poor }}$ and $\mathrm{H}_{F}^{O-\text { rich }}$ are calculated from standard reference states of each element at oxygen poor and oxygen rich conditions respectively. 

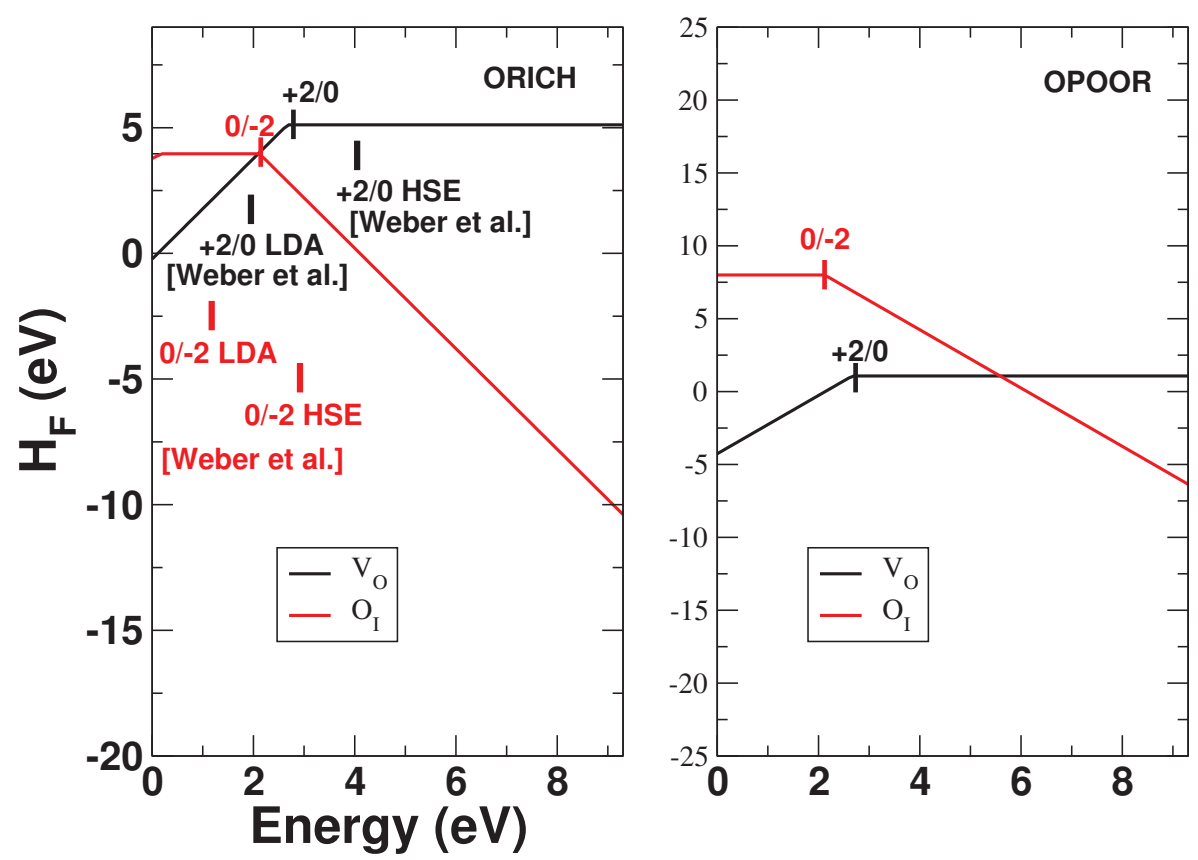

Figure 4: The defect formation energy, $\mathrm{H}_{f}$, of the oxygen interstitial and vacancy as a function of Fermi energy at oxygen rich (ORICH) and oxygen poor (OPOOR) conditions. Previous results with LDA and HSE from Weber et al. [45] are displayed. 

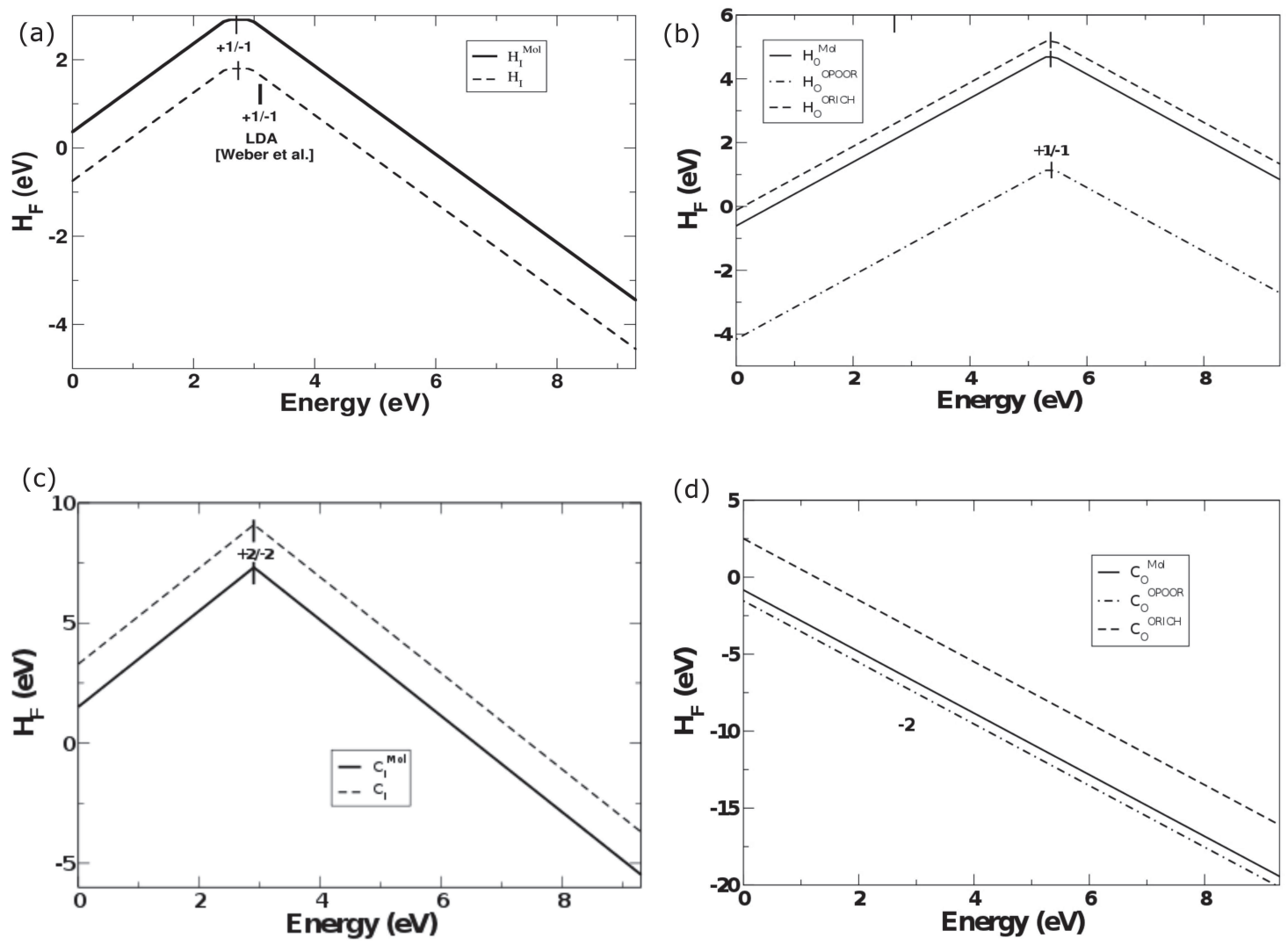

Figure 5: The calculated formation energy as a function of Fermi energy for (a) the hydrogen interstitial, $\mathrm{H}_{I}$, (b) hydrogen replacing oxygen, $\mathrm{H}_{O}$, (c) the carbon interstitial, $\mathrm{C}_{I},(\mathrm{~d})$ carbon replacing oxygen, $\mathrm{C}_{O}$. The formation energy is identical at oxygen rich and oxygen poor conditions from standard 

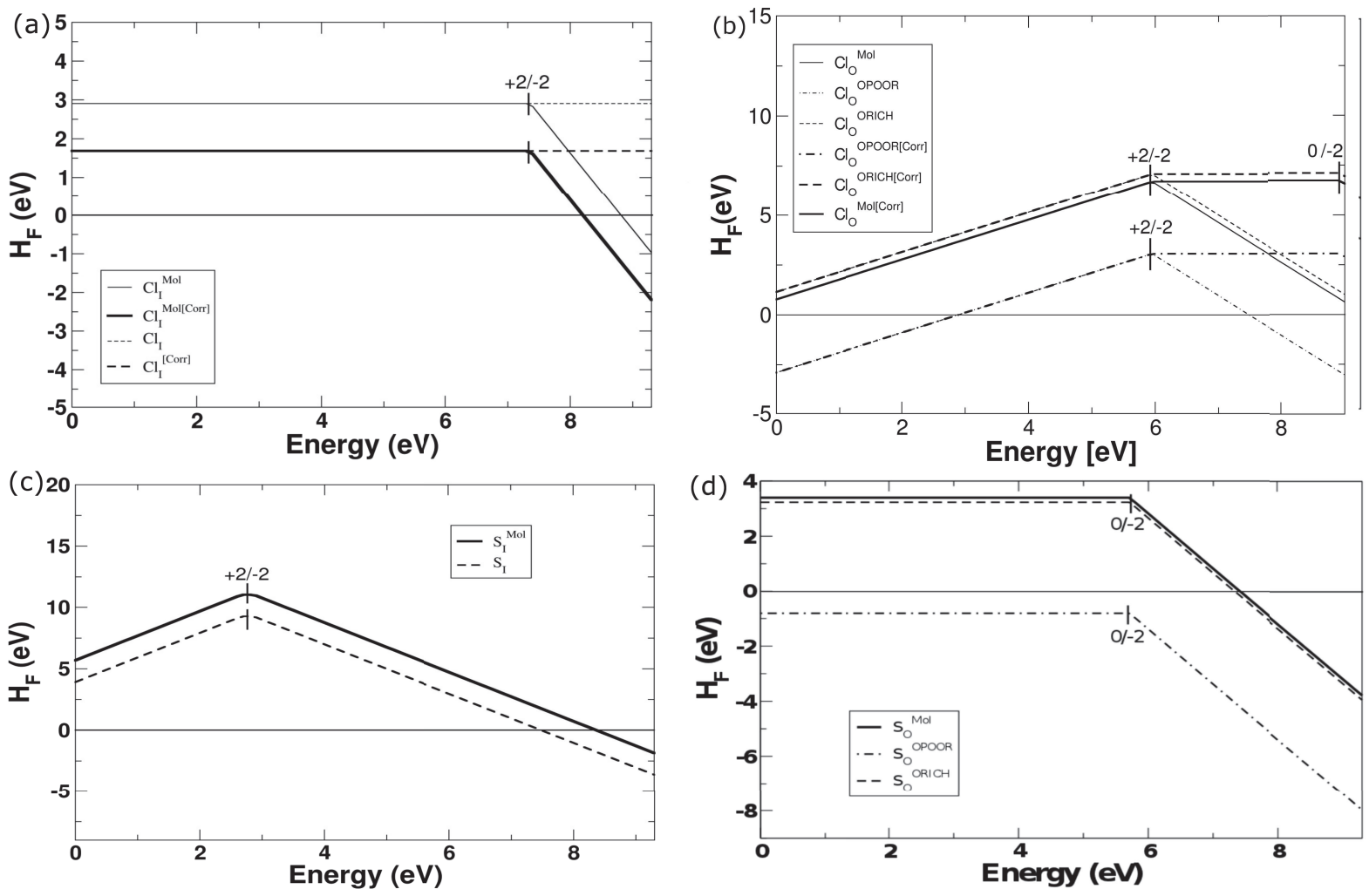

Figure 6: The calculated formation energy as a function of Fermi energy for (a) the chlorine interstitial, $\mathrm{Cl}_{I}$, (b) chlorine replacing oxygen, $\mathrm{Cl}_{O},(\mathrm{c}$ ) the sulfur interstitial, $\mathrm{S}_{I}$, (d) sulfur replacing oxygen, $\mathrm{S}_{O}$. $\mathrm{For} \mathrm{Cl}_{I}$, the formation energies including the band gap correction, denoted $\mathrm{Cl}_{I}^{M o l[C o r r]}$ and $\mathrm{Cl}_{I}^{[\text {Corr }]}$ are displayed. The same is valid for $\mathrm{Cl}_{O}^{\text {Mol }[\text { Corr }]}$ and $\mathrm{Cl}_{O}^{[C o r r]} \cdot \mathrm{Cl}_{I}^{M o l}$ an $\mathrm{Cl}_{I}^{M o l[C o r r]}$ are calculated from molecules in the gas phase of a typical CVD process. $\mathrm{Cl}_{I}$ and $\mathrm{Cl}_{I}^{[\text {Corr }]}$ are calculated from standard reference states of each element. The formation energy is identical at oxygen rich and oxygen poor conditions from standard reference states for $\mathrm{Cl}_{I}$ and $\mathrm{S}_{I}$. Therefore only one curve for each of these defects defect is displayed. 


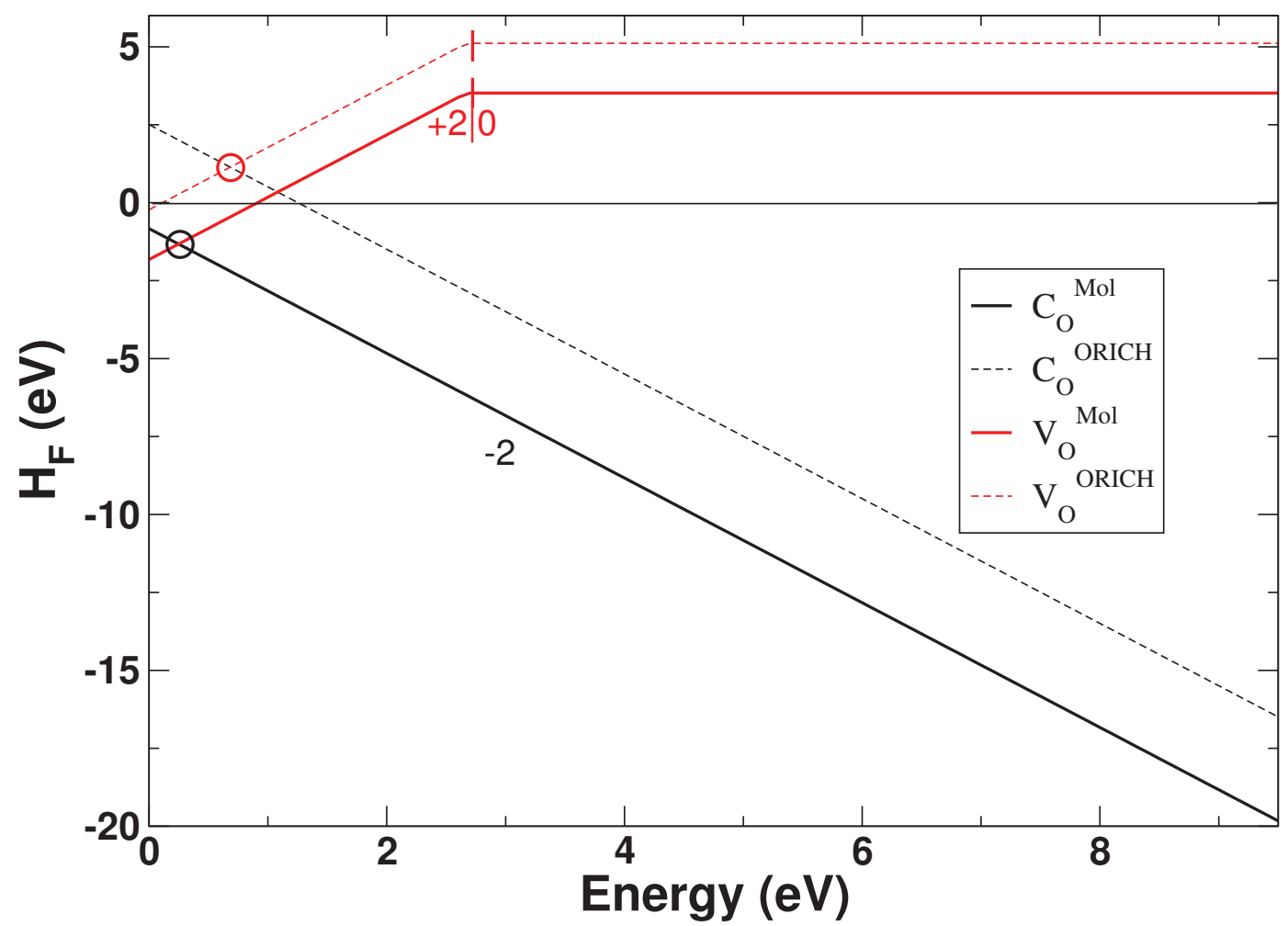

Figure 7: The formation energy as a function of Fermi energy for carbon replacing oxygen, $\mathrm{C}_{O}$ and the oxygen vacancy, $\mathrm{V}_{O}$. Only oxygen rich $(\mathrm{ORICH})$ conditions is displayed. 


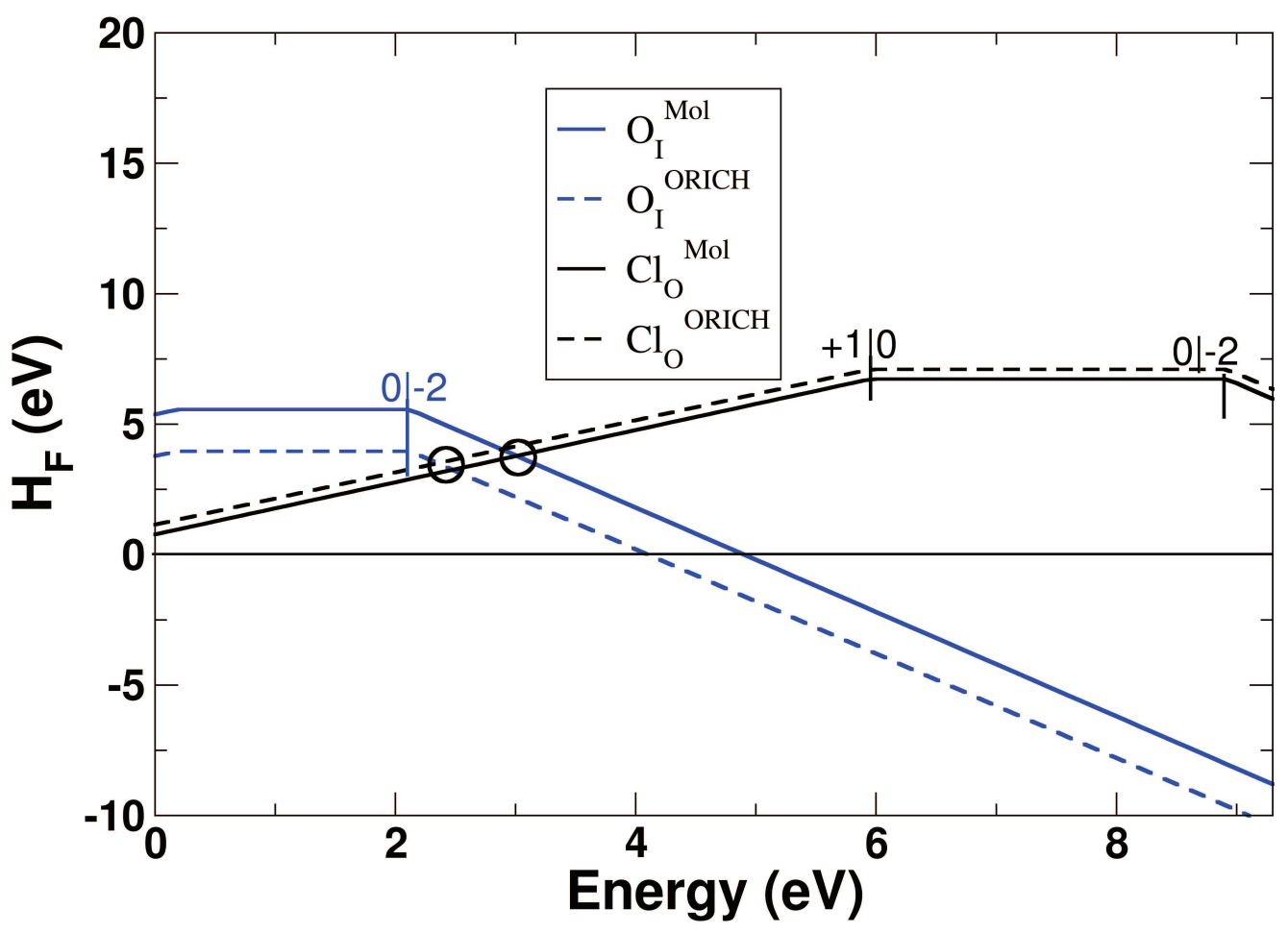

Figure 8: The formation energy as a function of Fermi energy for chlorine replacing oxygen, $\mathrm{Cl}_{O}$ and the oxygen interstitial, $\mathrm{O}_{I}$. Only the formation energies at oxygen rich (ORICH) conditions and including band gap correction from standard reference states are displayed. 


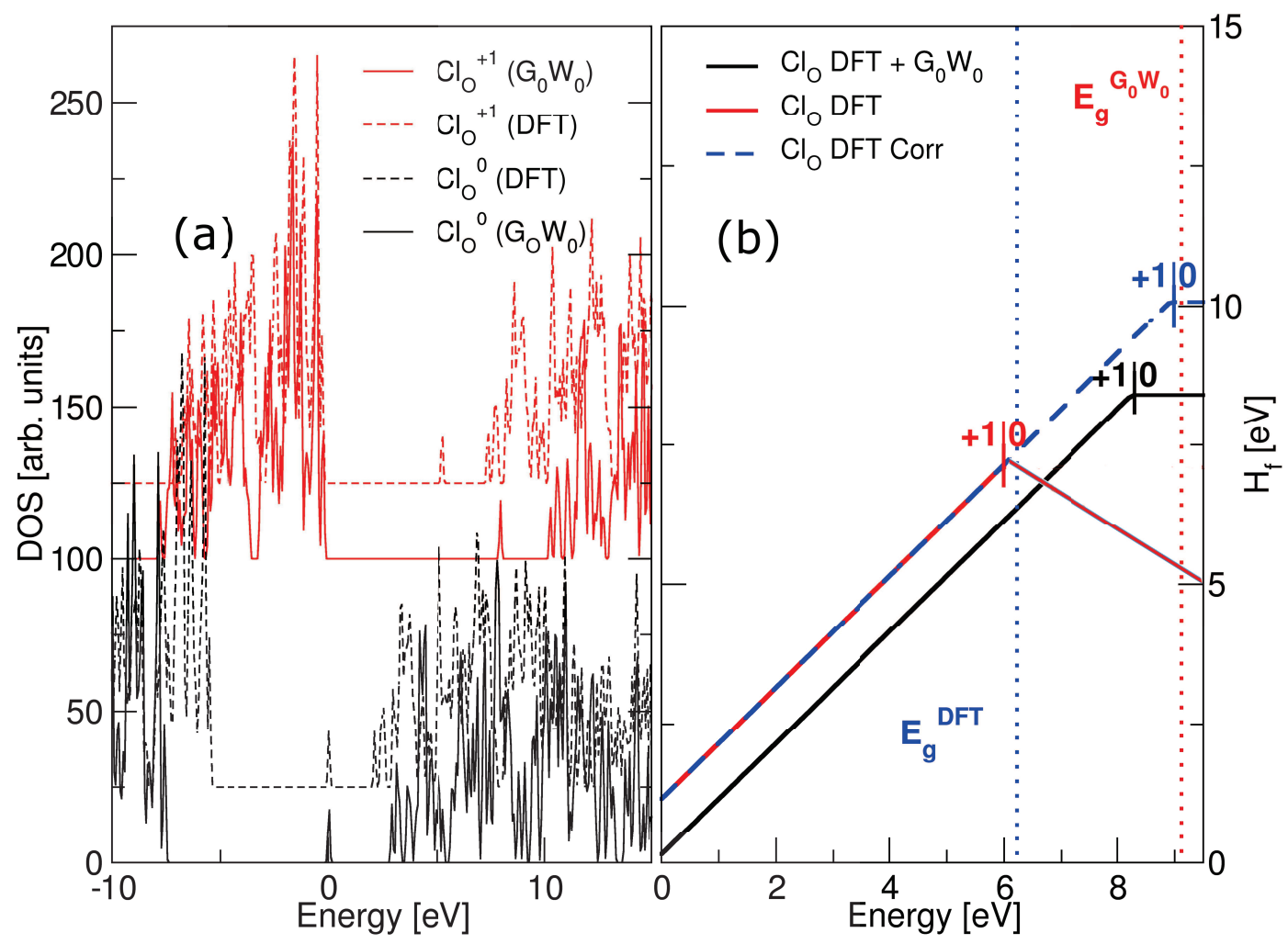

Figure 9: (a) The density of states for the neutral and +1 charged $\mathrm{Cl}$ replacing $\mathrm{O}, \mathrm{Cl}_{O}$, calculated from Density Functional Theory and $\mathrm{G}_{O} \mathrm{~W}_{O}$. (b) The formation energy of $\mathrm{Cl}$ neutral and +1 charge state from DFT and $\mathrm{G}_{0} \mathrm{~W}_{0^{-}}$ approximation as a function of Fermi energy. Only the formation energies at oxygen rich conditions from standard reference states are displayed. 


\section{References}

[1] M.S. Akselrod and V.S. Kortov. Radiation Protection Dosimetry, 33:123, 1990 .

[2] C. Richard A. Catlow Alexey A. Sokol, Aron Walsh. Phys. Rev. B, 63:024102, 2000.

[3] H. Altena, C. Colombier, and B. Lux. In J. Bloem, editor, Proc. 4th Eur. Conf., CVD, Eindhoven, Netherlands, page 451, 1983.

[4] Andre Anders. Cathodic Arcs: From Fractal Spots to Energetic Condensation. Springer, 2008.

[5] Jon M. Andersson, E. Wallin, V. Chirita, E.P. Munger, and U. Helmersson. Phys. Rev. B, 71:014101, 2005.

[6] Gordon Aylward and Tristan Findlay. SI Chemical data: 4th edition. John Wiley \& Sons, 1998.

[7] C. Björmander. Surface and Coatings Technology, 201:4032, 2006.

[8] A. Blomqvist, C. Arhammar, H. Pedersen, F. Silvearv, S. Norgren, and R. Ahuja. Surface and Coatings Technology, 206:1771-1779, 2011.

[9] P. E. Blöchl. Projector augmented-wave method. Phys. Rev. B, 50:17953 - 17979, 1994.

[10] F. Bruneval. Phys. Rev. Lett., 103:176403, 2009.

[11] A. Höglund C. W. M. Castleton and S. Mirbt. Phys. Rev. B, 73:035215, 2006.

[12] R. Colmet and R. Naslain. Wear, 80:221, 1982.

[13] C. Van de Walle and J. Neugebauer. J. Appl. Phys., 95:8, 2004.

[14] C.G. Van de Walle and J. Neugebauer. Nature, 423:626, 2003.

[15] B.D. Evans and M. Stapelbroek. Phys. Rev. B, 18:7089, 1978.

[16] E. Fredriksson and J-O. Carlsson. Thin Solid Films, 263:28, 1995.

[17] Judith Harl and Georg Kresse. Cohesive energy curves for noble gas solids calculated by adiabatic connection fluctuation-dissipation theory. Phys. Rev. B, 77:045136, 2008. 
[18] Kayun Jiang, Kostas Sarakinos, Stephanos Konstantinidis, and Jochen M. Schneider. J. Phys. D: Appl. Phys., 43:325202, 2010.

[19] M. Katrein, W. Schintlmeister, W. Wallgram, and U. Schleinkofer. Surf. Coat. Technol., 163-164:183, 2003.

[20] L. Kaufman and H. Bernstein. Computer calculation of phase diagrams. Academic Press, New York, 1970.

[21] J.-G. Kim, C.-S. Park, and J.S. Chun. Thin Solid Films, 97:97, 1982.

[22] G. Kresse and J. Furthmüller. Efficient iterative schemes for ab initio total-energy calculations using a plane-wave basis set. Phys. Rev. B, 54:11169-11186, 1996.

[23] Stefan Kurth, John P. Perdew, and Peter Blaha. Molecular and solid state tests of density functional approximations: Lsd, ggas and metaggas. Int. J. of Quant. Chem., pages 889-909, 1999.

[24] W. Lee and K. Lagerlof. J. Electron. Technol., 2:12777, 1985.

[25] J.-M. Lihrmann. J. of the Europeean Ceramic Society, 28:643-647, 2008.

[26] J.-M. Lihrmann, J. Tirlocq, P. Descamps, and F. Cambier. J. of the Europeean Ceramic Society, 19:2781-2787, 1999.

[27] J. Lindström and H. Schanchner. In H.E. Hinterman, editor, Proc. 3rd Eur.Conf., CVD, Neuch Áctel Switzerland, page 208, 1980.

[28] J. Lindström and K.G. Stjernberg. In J.-O. Carlsson and J. Lindström, editors, Proc. 5th Eur. Conf. CVD Uppsala Sweden, page 169, 1985.

[29] B. Ljungberg. Usp 5.66 782, 1998.

[30] B. Ljungberg. Ep 0784715 b1, 2001.

[31] B. Lux, C. Colombier, Altena, and Stjernberg. Thin Solid Films, 138:49, 1986 .

[32] G. Makov and M. C. Payne. Phys. Rev. B, 51:4014, 1995.

[33] P. Måtensson. Surface and Coatings Technology, 200:3676, 2006.

[34] Milton Ohring. Materials Science of Thin Films, 2nd Edition. Academic Press, 1992. 
[35] John P. Perdew, Kieron Burke, and Matthias Ernzerhof. Generalized gradient approximation made simple. Phys. Rev. Lett., 77:3865, 1996.

[36] C. Persson, Y-J. Zhao, S. Lany, and A. Zunger. Phys. Rev. B, 72:035211, 2005.

[37] Patrick Rinke, Anderson Janotti, Matthias Scheffler, and Chris G. Van de Walle. Phys. Rev. Lett., 102:026402, 2009.

[38] S. Ruppi. International Journal of Refractory Metals \& Hard Materials, 23, 2005 .

[39] W.C. Russell and C. Strandberg. Int. J. Refract. Met. Hard Mater., page 51, 1996.

[40] S. Pingfang and B. Sundman. Sgte substances database v3, 2004.

[41] N. Saunders and A.P. Miodownik. CALPHAD(Calculation of the phase diagram: A comprehensive guide). Pergamon Press, London, 1998.

[42] W. Schintlmeister, W. Wallgram, J. Kanz, and K. Gigl. Wear, 100:153, 1984

[43] B. W. Schmidt, B. R. Rogers, C. K. Gren, and T. P. Hanusa. Thin Solid Films, 518:3658, 2000.

[44] Ulf K.H. Smith and Jan N.Lindström. Usp 4619866, 1985.

[45] J.R. Weber, A. Janotti, and C.G. Van de Walle. Microelectronic Eng., 86:1756-1759, 2009.

[46] C. Wolverton and K. Hass. 492:44-48, 2010. 